\section{(2) OPEN ACCESS}

\title{
Nearly 20000 e-liquids and 250 unique flavour descriptions: an overview of the Dutch market based on information from manufacturers
}

\author{
Anne Havermans (10 , ${ }^{1}$ Erna J Z Krüsemann 지 , ${ }^{1,2}$ Jeroen Pennings, ${ }^{1}$ Kees de Graaf, ${ }^{2}$ \\ Sanne Boesveldt, ${ }^{2}$ Reinskje Talhout ${ }^{1}$
}

\begin{abstract}
- Additional material is published online only. To view please visit the journal online (http://dx.doi.org/10.1136/
\end{abstract} tobaccocontrol-2019-055303).

${ }^{1}$ Centre for Health Protection, National Institute for Public Health and the Environment, Bilthoven, The Netherlands ${ }^{2}$ Division of Human Nutrition and Health, Wageningen University, Wageningen, The Netherlands

Correspondence to Dr Anne Havermans, Centre for Health Protection, National Institute of Public Health and the Environment, Bilthoven 3720 BA, The Netherlands; anne.havermans@rivm.nl

Received 22 July 2019 Revised 25 September 2019 Accepted 30 September 2019 Published Online First 4 November 2019

\section{ABSTRACT \\ Objectives Flavours increase attractiveness of electronic cigarettes and stimulate use among vulnerable groups such as non-smoking adolescents. It is important for regulators to monitor the market to gain insight in, and regulate the range of e-liquid flavours that is available to consumers. E-liquid manufacturers are required to report key product information to authorities in the European Member States in which they plan to market their products. This information was used to provide an overview of e-liquid flavour descriptions marketed in the Netherlands in 2017.}

Methods Two researchers classified 19266 e-liquids into the 16 main categories of the e-liquid flavour wheel, based on information from four variables in the European Common Entry Gate system. Flavour descriptions were further specified in subcategories.

Results For 16300 e-liquids (85\%), sufficient information was available for classification. The categories containing the highest number of e-liquids were fruit (34\%), tobacco (16\%) and dessert (10\%). For all e-liquids, excluding unflavoured ones, 245 subcategories were defined within the main categories. In addition to previously reported subcategories, various miscellaneous flavours such as sandwich, buttermilk and lavender were identified.

Conclusions In 2017, 20000 e-liquids were reported to be marketed in the Netherlands, in 245 unique flavour descriptions. The variety of marketed flavour descriptions reflects flavour preference of e-cigarette users as described in literature. Our systematic classification of e-liquids by flavour description provides a tool for organising the huge variety in market supply, serves as an example for other countries to generate similar overviews and can support regulators in developing flavour regulations.

\section{INTRODUCTION}

The use of electronic cigarettes (e-cigarettes) has risen significantly over the recent years. ${ }^{12}$ Although e-cigarettes may provide a successful tool in smoking cessation, ${ }^{3}$ concerns have been raised about initiation of e-cigarette use among young non-smokers. ${ }^{4}$ An important factor in the high appeal of e-cigarettes to adolescents is the availability of a wide variety of e-liquid flavours. ${ }^{56}$ Especially sweet and fruity flavours are appreciated by young users. ${ }^{5-9}$ Not surprisingly, flavour descriptions play an important role in (online) e-cigarette promotion. ${ }^{10-12}$ In line with this, research showed that flavour-related advertisements are appealing to youth, and trigger increased interest in, purchasing and use of e-cigarettes. ${ }^{13-15}$ Unfortunately, it is difficult to monitor and control the purchase and use of e-cigarettes and e-liquids by young people, as these products are widely and readily available through tobacconists, vape shops and particularly the internet. ${ }^{16}$

This raises concerns, as e-cigarette emissions may contain toxic chemicals that can be harmful to health. ${ }^{17}$ In addition, a large proportion of available e-liquids contain the highly addictive compound nicotine. Teenagers and young adults are especially susceptible to develop addiction to nicotine, due to their ongoing brain maturation. ${ }^{18}$ Because the vast range of flavoured e-liquids is attractive to vulnerable consumer groups (eg, adolescents and young adults), there is a clear need for regulation. Regulation of and research on e-liquid flavours can focus on consumer flavour perception (sensory science), flavouring ingredients that compose a perceived flavour (chemical analysis), and flavour descriptions that are used for marketing purposes. For example, current European and US regulations prohibit cigarettes and roll-your-own tobacco with a characterising flavour, ${ }^{19}{ }^{20}$ which is monitored by a sensory panel of trained experts. ${ }^{21} 22$ Recently, more and more countries also announced regulatory actions regarding e-cigarette flavours. For example, the US Food and Drug Administration (FDA) has announced regulation to limit sales of e-cigarettes to minors ${ }^{23}$ and to ban all e-cigarette flavours other than tobacco. ${ }^{24}$ With the current study, we aim to support policymakers in regulating the marketing and promotion of e-liquids with flavour descriptions that may increase product interest and appeal.

In order to develop such regulation regarding the promotion of flavoured e-liquids, it is important to monitor the market as to obtain a better understanding of the full range of products and flavours that are advertised to consumers. However, surveillance of the (online) e-cigarette marketplace can be challenging due to its rapidly changing and increasingly diverse character. ${ }^{25}$ In addition, current estimations of available e-liquid flavours often rely on survey data ${ }^{5}{ }^{26-28}$ rather than a complete census of products available on the market. Thus, at this moment, a complete overview of the supply of e-liquid flavour descriptions in any market worldwide is lacking.

However, according to the European Tobacco Product Directive, ${ }^{19}$ e-cigarette and e-liquid manufacturers are required to provide key product 
information on the branding and composition of their products to authorities of the European Member States in which they plan to place their product on the market. This information provides a unique opportunity to establish an overview of the e-cigarette market in a particular European Member State. Here, we used e-liquid brand names and other flavour-related information as framed by the industry, which we refer to as 'flavour descriptions' in this article (by others potentially colloquially referred to as 'flavour names'). This means that we did not obtain sensory nor chemical data about (the perception or composition of) e-liquid flavours. Hence, this paper presents a comprehensive overview of flavour descriptions of e-liquids reported by manufacturers to be marketed in the Netherlands in 2017.

\section{METHODS}

\section{Data collection and preparation}

Flavour-related information about all products in the Dutch section of the European Common Entry Gate (EU-CEG) system ${ }^{29}$ was extracted on 30 November 2017. Only information from the category 'refillable e-liquids and cartridges' (not 'devices' or 'individual parts') was selected for this study. When there were multiple presentations of the same product (eg, one e-liquid marketed in different packages), one presentation was randomly selected. This was the case for 3922 products. Eight products were excluded due to incomplete information. E-liquids with the same flavour description, but different nicotine concentrations were considered different products and therefore separately included. The final dataset consisted of 19266 products.

There is no required field in the EU-CEG system ${ }^{29}$ to describe a product's flavour. However, information about a product's flavour can often be inferred from its brand name. In addition, some manufacturers provided a description of their product's flavour in the fields 'Product Identification' and/or 'General Comment', which can be used optionally to provide additional product information. For our analyses, we therefore retrieved and combined all relevant flavour-related information from the following fields in the EU-CEG system: 'Brand Name', 'Brand Subtype Name', 'Product Identification' and 'General Comment'. For example, all flavour-related information obtained from one (fictional) e-liquid could be 'Dancer-Purple Blue Berry $-12 \mathrm{mg} / \mathrm{mL}$ '. This information was used for classification of e-liquids using the recently published e-liquid flavour wheel. ${ }^{30}$ Thus, the flavour-related information that we retrieved from EU-CEG (brand names, information from other fields, or both) was reported by manufacturers to describe their product's flavour, and was recoded by us to a flavour description following a standardised approach (ie, classification according to the flavour wheel).

In case insufficient flavour-related information was available in the database to directly classify an e-liquid $(n=7116 ; 37 \%$ of total sample), a standardised internet search was conducted (www.google.com): input for the search was all flavour-related information of the e-liquid of interest plus the term 'e-liquid'. Resulting websites were consulted in consecutive order until a flavour description was found. E-liquids that were not found on the Internet ( $n=1680 ; 9 \%$ of total sample) were considered 'unclassifiable'. When the information from the EU-CEG system was too general to identify a specific e-liquid using the internet search (eg, only referring to a brand or product range), the product was also considered unclassifiable.

In order to establish interrater reliability, two research assistants first independently classified a random sample of 166 e-liquids. The Cohen's Kappa R, calculated using R statistical software V.3.4.3, reached 0.86 , which is considered a strong level of agreement. ${ }^{31} \mathrm{Next}$, the same two research assistants each classified half of the total set of e-liquids. Finally, two of the authors checked the complete set for inconsistencies.

\section{Flavour classification}

e-Liquids were classified in a consistent manner according to the e-liquid flavour wheel. ${ }^{30}$ The flavour wheel consists of an inner wheel with 16 main categories: tobacco, menthol/mint, nuts, spices, coffee/tea, alcohol, other beverages, fruit-berries, fruitcitrus, fruit-tropical, fruit-other, dessert, candy, other sweets, other flavours and unflavoured. In the outer wheel, the main categories are further specified using subcategories. Because the subcategories of the published flavour wheel are not all encompassing, flavour descriptions that did not match the existing subcategories were regarded new subcategories. A detailed description of the classification approach can be found in the online supplementary materials.

\section{Data analyses}

The classified set of 19266 products was analysed in R statistical software V.3.4.3. For each of the 16 main flavour categories, the following values were determined: the number of unique subcategories; the number of products (within each main and subcategory); the number of products with a secondary flavour description; the number of unique secondary flavour descriptions; and the average number of secondary flavour descriptions (within each main and subcategory).

Finally, the nicotine concentrations as declared by the industry were analysed. E-liquids with a package unit other than one and a volume other than $10 \mathrm{~mL}$ were excluded from this analysis $(n=2427)$, because declared nicotine values of these products could not be related to a unit. E-liquids with unusual nicotine values that could not be related to a common nicotine unit $(\mathrm{n}=359)$ or without data on their nicotine concentration at all $(n=1343)$ were excluded. This resulted in a total set of 12551 e-liquids for nicotine analysis. These e-liquids were divided into five groups according to their declared nicotine values, to represent the most common nicotine concentrations available on the Dutch market $(0,3,6,12$ and $18 \mathrm{mg} / \mathrm{mL})$. Most e-liquids contained a nicotine value that exactly matched these concentrations. Some values slightly deviated, therefore the following ranges were maintained: $0 \mathrm{mg} / \mathrm{mL}(\mathrm{n}=381), 3 \mathrm{mg} / \mathrm{mL}$ (range $>0$ and $<4.5 ; \mathrm{n}=2836$ ), $6 \mathrm{mg} / \mathrm{mL}$ (range $\geq 4.5$ and $<9$; $\mathrm{n}=3702$ ), $12 \mathrm{mg} / \mathrm{mL}$ (range $\geq 9$ and $<15 ; \mathrm{n}=3229$ ) and $18 \mathrm{mg} /$ $\mathrm{mL}$ (range $\geq 15$ and $<20 ; \mathrm{n}=2403$ ).

\section{RESULTS}

\section{Primary flavour descriptors}

A total of 19266 e-liquids were submitted to the Dutch EU-CEG system on 30 November 2017. For 16300 (85\%) e-liquids, sufficient flavour-related information was available for classification of the product into one of the 16 main categories of the e-liquid flavour wheel. ${ }^{30}$ Figure 1 shows the percentage of e-liquids classified within each of the main categories (ie, reflecting a product's general flavour description). The categories containing the highest number of e-liquids were tobacco $(\mathrm{n}=2667,16 \%)$, fruitother $(n=2506,15 \%)$, fruit-berries $(n=2164,13 \%)$ and dessert $(\mathrm{n}=1710,10 \%)$. Overall, $34 \%$ of the e-liquids were classified in one of the fruit categories (ie, berries, citrus, tropical and other fruit). The smallest category was other flavours $(\mathrm{n}=169,1 \%)$, followed by spices $(\mathrm{n}=176,1 \%)$, nuts $(\mathrm{n}=179,1 \%)$ and unflavoured $(\mathrm{n}=266,2 \%)$. 


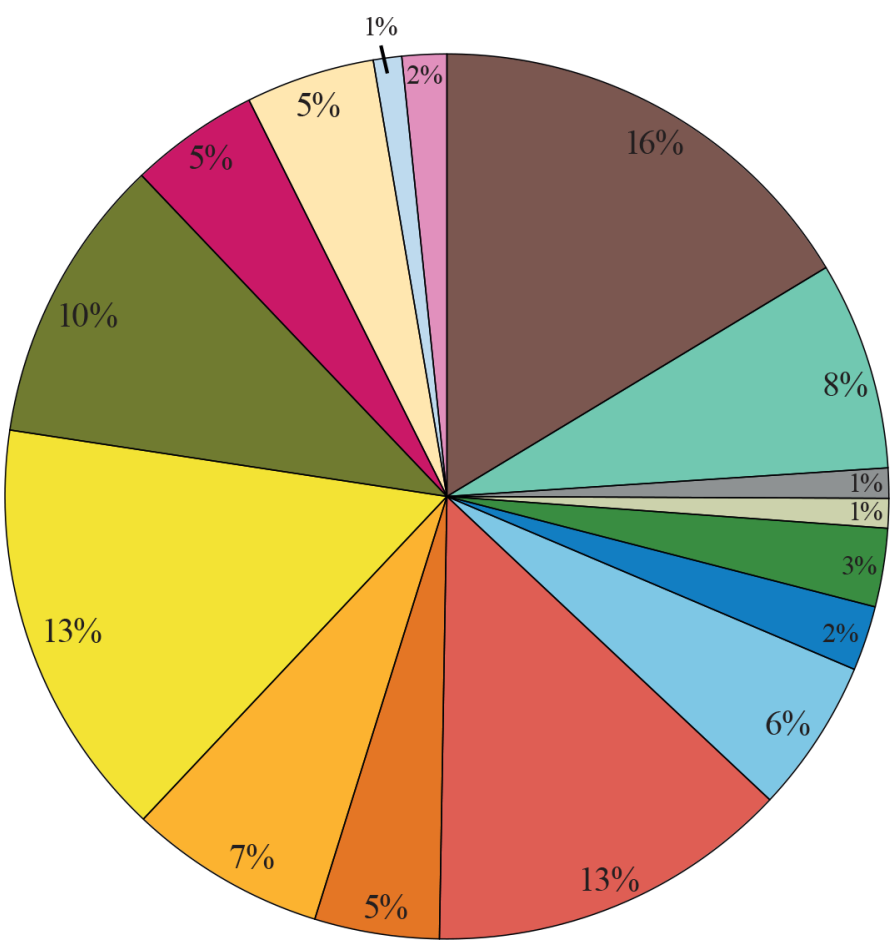

Tobacco $(\mathrm{n}=2667)$
Menthol $/$ mint $(\mathrm{n}=1240)$
Nuts $(\mathrm{n}=179)$
Spices $(\mathrm{n}=176)$
Coffee/tea $(\mathrm{n}=467)$
Alcohol $(\mathrm{n}=386)$
Other beverages $(\mathrm{n}=915)$
Fruit - berries $(\mathrm{n}=2164)$
Fruit - citrus $(\mathrm{n}=743)$
Fruit - tropical $(\mathrm{n}=1173)$
Fruit - other $(\mathrm{n}=2506)$
Dessert $(\mathrm{n}=1710)$
Candy $(\mathrm{n}=771)$
Other sweets $(\mathrm{n}=768)$
Other flavors $(\mathrm{n}=169)$
Unflavored $(\mathrm{n}=266)$

Figure 1 Distribution of the main flavour categories representing e-liquid availability on the Dutch market. Classification was based on brand names and flavour-related information as reported by manufacturers. Sequence and colours of the categories are based on the e-liquid flavour wheel. $^{30}$

For each main category, except for unflavoured, multiple subcategories (ie, specific flavour descriptions) were defined, ranging from 4 (spices) to 46 (dessert). Overall, 245 unique subcategories were distinguished. Figure 2 shows the percentage of e-liquids within each subcategory, for each of the 16 main categories separately. All subcategories, as well as the number of e-liquids within each subcategory are reported in online supplementary table S1.

'Other flavours' category

A total of 169 e-liquids were classified as other flavours, meaning that their primary flavour descriptor (based on brand name and flavour-related information from manufacturers) could not be classified into one of the other 15 main categories of the flavour wheel. Based on the products' flavour-related information, 16 subcategories were identified within the other flavours category. These subcategories were related to various flower and plant-related flavours (flowers, cherry blossom, roses, violet, lavender, hibiscus, honeysuckle, verbena, woodruff); vegetables (cucumber, rhubarb, fennel); bread-related flavours (bread, sandwich); and jam and cannabis.

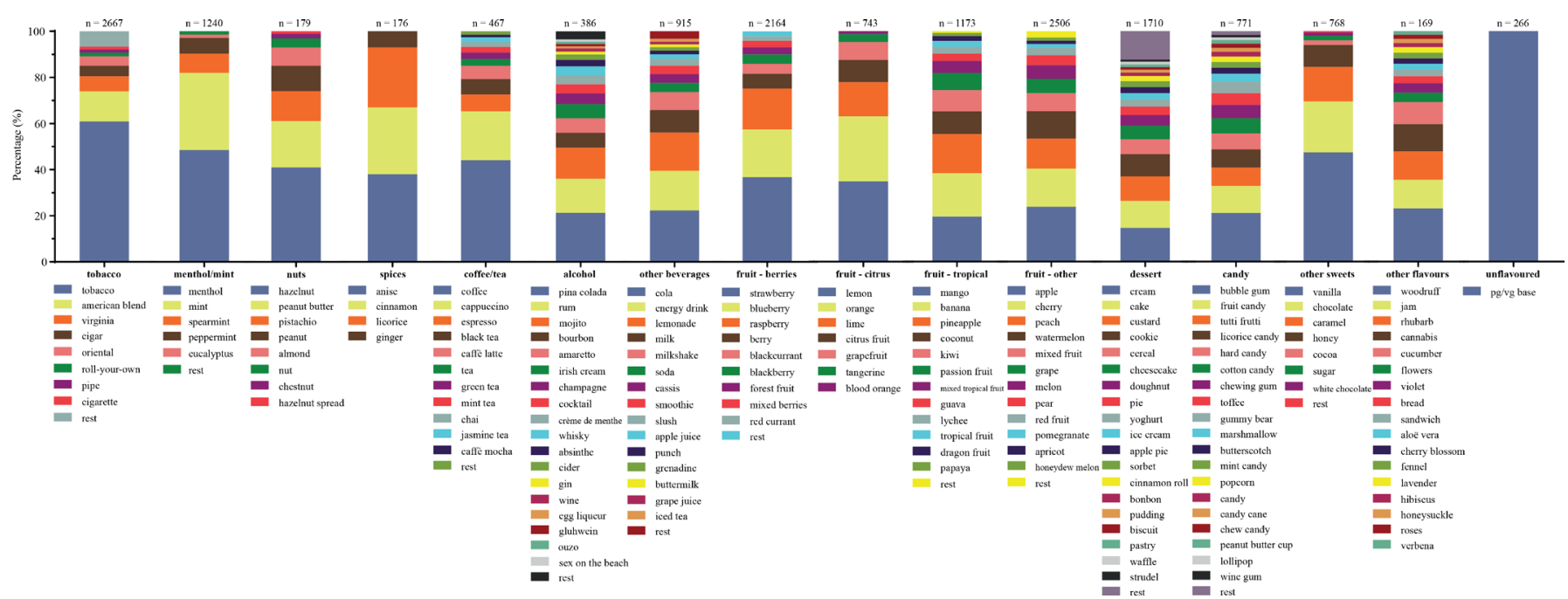

Figure 2 Distribution of subcategories (ie, specific e-liquid flavours) within each of the main flavour categories of the e-liquid flavour wheel. ${ }^{30}$ Classification was based on brand names and flavour-related information as reported by manufacturers. The subcategories containing $<1 \%$ of the e-liquids within that main category were combined into a 'rest' subcategory. 


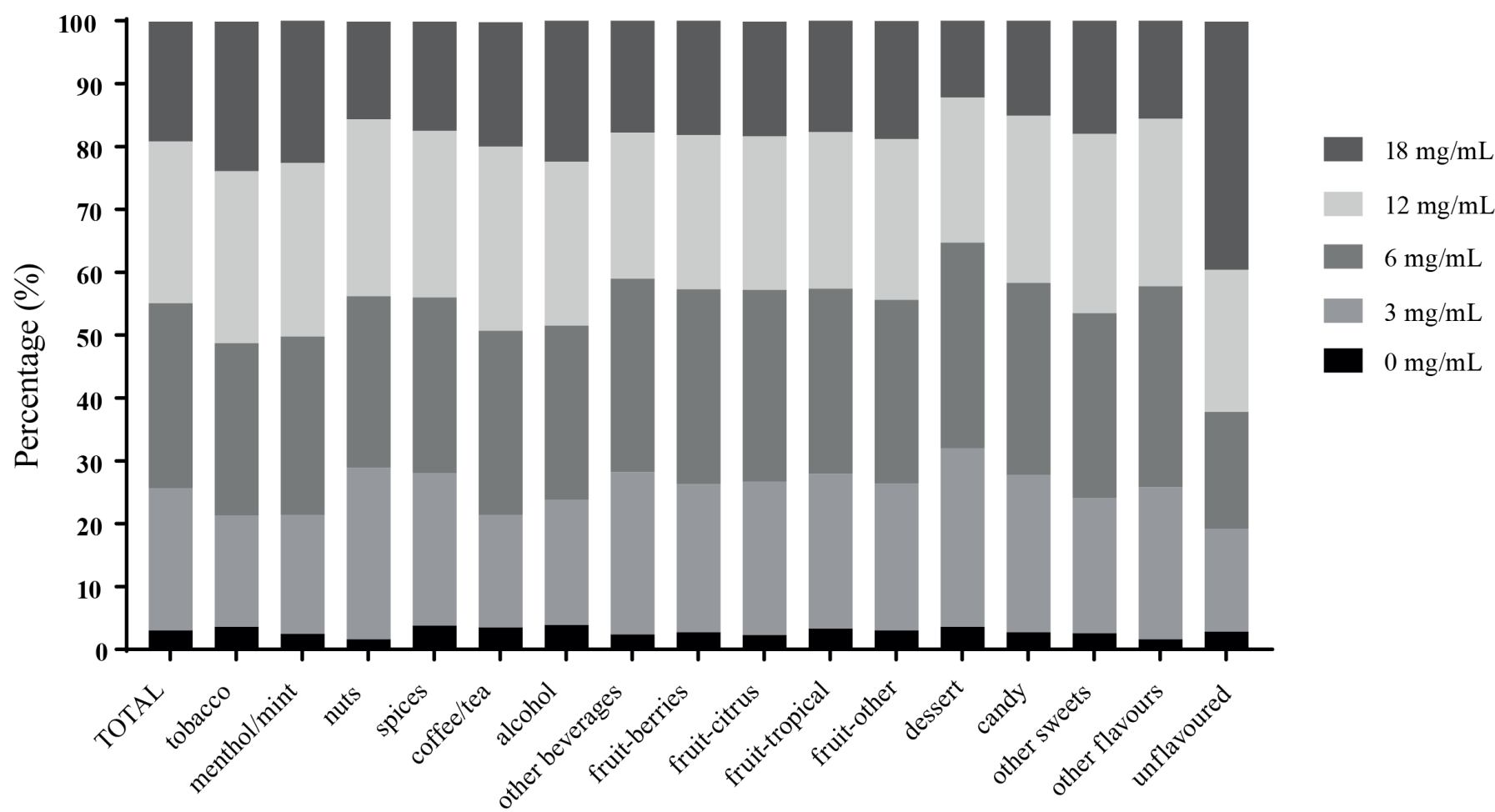

Figure 3 Nicotine concentrations within each of the main categories of the e-liquid flavour wheel. ${ }^{30}$ Nicotine values reported by manufacturers in the EU-CEG system were categorised into five groups representing the most common nicotine concentrations available on the Dutch market. EU-CEG, European Common Entry Gate.

\section{Secondary flavour descriptors}

For 5676 e-liquids (29\%), one or more secondary flavour descriptors could be distinguished (based on brand name and flavour-related information). Of the e-liquids containing at least one secondary flavour descriptors, the average number of secondary flavour descriptors was 1.6. The number of products containing secondary flavour descriptors was highest within the dessert category (66\%) and lowest within the menthol/mint category $(17 \%)$.

\section{Nicotine concentrations}

Nicotine concentrations ranged from 0 to $20 \mathrm{mg} / \mathrm{mL}$, which is the current legal maximum in the EU. Of the 12551 e-liquids that were included in the nicotine analysis, only $3 \%$ was reported to be nicotine-free $(0 \mathrm{mg} / \mathrm{mL})$. The percentage of e-liquids with high nicotine concentrations $(18 \mathrm{mg} / \mathrm{mL})$ was highest within the unflavoured category (40\%). Distribution of nicotine concentrations per main flavour category is visualised in figure 3 .

\section{DISCUSSION}

This study presents a comprehensive overview of flavour descriptions of e-liquids reported to be marketed in the Netherlands in 2017. Using brand names and flavour-related information provided by manufacturers through the EU-CEG system, ${ }^{29}$ e-liquids were classified into the main and subcategories of the e-liquid flavour wheel. ${ }^{30}$ We found that $\sim 20000$ e-liquids were reported, having 245 unique flavour descriptions. Approximately one-third of the e-liquids was classified as having a fruit flavour (berries, citrus, tropical or other fruits). Subsequently, the largest categories were tobacco, dessert and menthol/mint. In line with this, literature shows that fruit and sweet flavours are the most commonly used flavours among both young and adult e-cigarette users. ${ }^{5792732}$ Furthermore, adults who completely substituted the use of conventional cigarettes by e-cigarettes have often initiated e-cigarette use with fruity flavours rather than tobacco flavours, or switched from tobacco to non-tobacco e-liquid flavours over time. $^{728}$ On the other hand, dual users (using e-cigarettes as well as combustible tobacco) most commonly use tobacco-flavoured e-liquids, ${ }^{79}$ which is the second largest flavour category in the Netherlands based on the results of our current study. The flavour descriptions by which e-liquids are marketed, based on brand names and flavour-related information from manufacturers, thus seem to match flavour preferences as described in literature.

\section{Primary flavour descriptors}

Overall, at least $56 \%$ of the e-liquids was classified in a category that represents a sweet flavour (ie, the ones classified as other beverages, fruit, dessert, candy or other sweets). This large number of e-liquids marketed as sweet may be a response to sweet taste being the most preferred taste by all age groups. ${ }^{33}$ Surprisingly, while umami, or savoury, is typically also a popular taste in foods (eg, broth, cooked meat, fish and vegetables), not many e-liquids with a flavour description related to savoury food products exist. It would be interesting for future research to investigate why the market for savoury e-liquid flavours seems to be limited.

Within the main flavour categories, multiple subcategories were defined ( 245 in total, ranging from 4 to 46 per main category). However, regardless of the total number of subcategories within a particular main category, only four subcategories per main category were needed to classify roughly half of the e-liquids (figure 2). For example, while the alcohol category contained 23 unique subcategories, more than half of all e-liquids in the alcohol main category were classified in the four largest subcategories: piña colada, rum, mojito and bourbon. 
Similarly, while the dessert category contained 46 subcategories, almost half of all e-liquids in the dessert category were classified in the following 4 subcategories: cake, cookie, cream, custard. This shows that the main categories were dominated by only a few subcategories.

\section{Nicotine concentrations}

In the Netherlands, e-liquids are sold in nicotine concentrations ranging from 0 to $20 \mathrm{mg} / \mathrm{mL}$. The percentage of e-liquids with a high nicotine concentration (ie, category of $18 \mathrm{mg} / \mathrm{mL}$ ) was relatively high in the unflavoured category, as compared with the other main categories of the flavour wheel. A reason for this may be that unflavoured e-liquids, some of them marketed as 'nicotine booster', are mainly purchased to add nicotine to hand-made e-liquid mixes. Finally, only $3 \%$ of the e-liquids were marketed as nicotine-free $(0 \mathrm{mg} / \mathrm{mL})$. However, we excluded e-liquids without any data on their nicotine concentration, while manufacturers of nicotine-free e-liquids may purposely not have submitted nicotine-related information for these e-liquids. Also, in the Netherlands, nicotine-free e-liquids were not required to be registered in the EU-CEG system at the time of this study. ${ }^{34}$ Therefore, our results may provide an underestimation of the actual number of nicotine-free e-liquids on the Dutch market.

\section{Limitations}

For this study, we used flavour-related information retrieved from a set of variables in the EU-CEG system (ie, 'Brand Name', 'Brand Subtype Name', 'Product Identification' and 'General Comment'). ${ }^{29}$ This information was submitted by manufacturers, and does not necessarily represent the flavour as perceived by consumers or the flavour descriptions used for marketing on web shops. Because of limited or unspecific flavour-related information from EU-CEG, classification of approximately one-third of the e-liquids required an internet search, and eventually, $15 \%$ of the e-liquids could not be classified in any of the flavour wheel categories. Some of these products may have been removed from the market in the period between data extraction and the time of data analysis. Accordingly, it should be noted that information retrieved from the EU-CEG system represents a snapshot of the market on a single day. In addition, as products should be notified in the EU-CEG system at least 6 months prior to being placed on the market, it is possible that some products submitted to the EU-CEG system were not actually on the market at the time of data extraction.

Importantly, as information in the EU-CEG is provided by the e-cigarette industry, without the aim of sustaining research, it should be treated with appropriate caution. In order to verify and support conclusions based on EU-CEG data, independent market research may be conducted. After all, strict surveillance of submitted industry data is needed to ensure an accurate dataset for future use. A more elaborate discussion on the limitations (and strengths) of the data source and approach to flavour classification can be found in the online supplementary materials.

\section{Policy recommendations}

The fact that e-liquids are marketed with such a large variety of-especially sweet-flavour descriptions is highly concerning in the light of previous research demonstrating the great appeal of such flavours to youth, and therefore underlines a significant need for regulation. That is, in order to reduce e-cigarette appeal for adolescents and young adults, the abundant landscape of flavours in which e-liquids are promoted should be restricted. This can be achieved, for instance, by only allowing e-liquid flavours to be described as one of the 16 general terms that make up the main categories of the flavour wheel (inner wheel). Regulating e-liquid flavour names to the actual 16 categories also prevents the marketing of products with extraordinary names that may be particularly appealing to youth, such as unicorn-themed names. ${ }^{32}$ Taking potential flavour regulation a step further, specific flavour categories that are proven to be particularly attractive to vulnerable user groups (ie, non-smokers and youth), such as candy and dessert flavours, could be banned completely. Such forms of regulation mostly target the way e-liquids are marketed, and not the actual perceived flavour or composition of the products, which will make enforcement more feasible. However, the potential negative effect of implementing such rules on smokers aiming to switch towards exclusive e-cigarette use and thereby quit smoking should be considered as well.

\section{CONCLUSIONS}

This study was the first to use industry data to classify marketed e-liquids by flavour descriptions using brand names and flavourrelated information. We showed that, in 2017, the Dutch market comprised $\sim 20000$ e-liquids in 245 unique flavour descriptions. One-third of the (classifiable) e-liquids was marketed as having a fruit flavour, and over half of the e-liquids as having any type of sweet flavour. The marketed variety of e-liquid flavour descriptions as identified in this study reflects flavour preferences of e-cigarette users as described in previous literature. Our approach can serve as an example for other countries to generate a similar overview. This is especially relevant for European Member States as they have the opportunity to retrieve a similar dataset from the EU-CEG system. This allows comparing the landscape of advertised e-liquid flavour descriptions between local markets. Furthermore, our systematic classification of e-liquids by flavour description provides structure in the huge variety in market supply, and can serve as a tool for policymakers in developing rules for e-liquid flavour regulation.

What this paper adds

What is already known on this subject

- A main reason for the high appeal of e-cigarettes to young people is the availability of a wide variety of, especially sweet, e-liquid flavours. Since e-liquids are widely and readily available to young people, and may be harmful to health, there is a clear need for flavour regulation.

What important gaps in knowledge exist on this topic

- At this time, regulators do not have a complete overview of available e-liquids and flavour descriptions on their regional markets. This information is needed in order to monitor, and potentially regulate, the increasingly large and diversifying e-cigarette market.

What this paper adds

- This study was the first to use industry data to classify marketed e-liquids into the categories of the e-liquid flavour wheel using flavour-related information from manufacturers. Classifying e-liquids by flavour description helps to focus regulation on flavour categories that are for example most attractive to specific consumer groups and/or particularly contain toxic flavourings. Our approach can serve as an example for other regional markets to perform similar analyses.

Acknowledgements The authors would like to thank Linde Huis in 't Veld and Amy van Beers for their contribution to the e-liquid classification. 
Contributors AH and EJZK contributed equally. AH, EJZK and RT conceptualised and designed the study. JP prepared and analysed the data. AH and EJZK supervised e-liquid classification and wrote the manuscript. SB, KdG, JP and RT provided critical feedback on the manuscript.

Funding The Ministry of Health, Welfare and Sport (VWS), project 5.7.1.

Competing interests None declared.

Patient consent for publication Not required.

Provenance and peer review Not commissioned; externally peer reviewed.

Data availability statement Processed data classification tools are available upon reasonable request.

Open access This is an open access article distributed in accordance with the Creative Commons Attribution Non Commercial (CC BY-NC 4.0) license, which permits others to distribute, remix, adapt, build upon this work non-commercially, and license their derivative works on different terms, provided the original work is properly cited, appropriate credit is given, any changes made indicated, and the use is non-commercial. See: http://creativecommons.org/licenses/by-nc/4.0/.

\section{ORCID iDs}

Anne Havermans http://orcid.org/0000-0003-2874-6560

Erna J Z Krüsemann http://orcid.org/0000-0003-3552-8190

\section{REFERENCES}

1. Filippidis FT, Laverty AA, Gerovasili V, et al. Two-year trends and predictors of ecigarette use in 27 European Union member states. Tob Control 2017;26:98-104.

2. McMillen RC, Gottlieb MA, Shaefer RMW, et al. Trends in electronic cigarette use among U.S. adults: use is increasing in both smokers and nonsmokers. Nicotine Tob Res 2015;17:1195-202.

3. Rahman MA, Hann N, Wilson A, et al. E-Cigarettes and smoking cessation: evidence from a systematic review and meta-analysis. PLoS One 2015;10:e0122544.

4. Soneji S, Barrington-Trimis JL, Wills TA, et al. Association between initial use of ecigarettes and subsequent cigarette smoking among adolescents and young adults: a systematic review and meta-analysis. JAMA Pediatr 2017;171:788-97.

5. Schneller LM, Bansal-Travers M, Goniewicz ML, et al. Use of flavored electronic cigarette refill liquids among adults and youth in the US-Results from wave 2 of the population assessment of tobacco and health study (2014-2015). PLoS One 2018;13:e0202744.

6. Villanti AC, Johnson AL, Ambrose BK, et al. Flavored tobacco product use in youth and adults: findings from the first wave of the path study (2013-2014). Am J Prev Med 2017;53:139-51.

7. Harrell MB, Weaver SR, Loukas A, et al. Flavored e-cigarette use: characterizing youth, young adult, and adult users. Prev Med Rep 2017;5:33-40.

8. Pepper JK, Ribisl KM, Brewer NT. Adolescents' interest in trying flavoured e-cigarettes. Tob Control 2016;25:ii62-6.

9. Zare S, Nemati M, Zheng Y. A systematic review of consumer preference for e-cigarette attributes: flavor, nicotine strength, and type. PLoS One 2018;13:e0194145.

10. Liang $Y$, Zheng $X$, Zeng DD. Impact of Flavor on Electronic Cigarette Marketing in Social Media. In: Zheng X, Zeng DD, Chen H, eds. Smart health. Cham: Springer International Publishing, 2016: 278-83.

11. Grana RA, Ling PM. "Smoking revolution": a content analysis of electronic cigarette retail websites. Am J Prev Med 2014;46:395-403.

12. Soule EK, Sakuma K-LK, Palafox S, et al. Content analysis of Internet marketing strategies used to promote flavored electronic cigarettes. Addict Behav 2019;91:128-35.

13. Garrison KA, O'Malley SS, Gueorguieva R, et al. A fMRI study on the impact of advertising for flavored e-cigarettes on susceptible young adults. Drug Alcohol Depend 2018;186:233-41.
14. Vasiljevic M, Petrescu DC, Marteau TM. Impact of advertisements promoting candy-like flavoured e-cigarettes on appeal of tobacco smoking among children: an experimental study. Tob Control 2016;25:e107-12.

15. Farrelly $\mathrm{MC}$, Duke JC, Crankshaw EC, et al. A randomized trial of the effect of e-cigarette TV advertisements on intentions to use e-cigarettes. Am J Prev Med 2015;49:686-93.

16. Zhu S-H, Sun JY, Bonnevie E, et al. Four hundred and sixty brands of e-cigarettes and counting: implications for product regulation. Tob Control 2014;23:iii3-9.

17. Hutzler $C$, Paschke $M$, Kruschinski $S$, et al. Chemical hazards present in liquids and vapors of electronic cigarettes. Arch Toxicol 2014;88:1295-308.

18. England LJ, Bunnell RE, Pechacek TF, et al. Nicotine and the developing human: a neglected element in the electronic cigarette debate. Am J Prev Med 2015;49:286-93.

19. The European Parliament and The Council of the European Union. Directive 2014/40/ $\mathrm{EU}$ on the approximation of the laws, regulations and administrative provisions of the member states concerning the manufacture, presentation and sale of tobacco and related products and repealing Directive 2001/37/EC. Official Journal of the European Union 2014; 127.

20. The Senate and House of Representatives of the United States of America in Congress Public law 111-31: family smoking prevention and tobacco control and federal retirement reform. in: Congress T, ED; 2009: 1776-858.

21. Chambers $E$, Paschke T. Validation of a recommended practice for assessing "characterizing flavor" to meet requirements of the EU Tobacco Product Directive (2014/40/EU). J Sens Stud;28:e12511.

22. Krüsemann EJZ, Lasschuijt MP, de Graaf C, et al. Sensory analysis of characterising flavours: evaluating tobacco product odours using an expert panel. Tob Control 2019;28:152-60.

23. U.S. Department of Health and Human Services FaDA. Modifications to compliance policy for certain deemed tobacco products. FDA-2019-D-0661. Rockville, MD Food and Drug Administration; 2019

24. FDA. Trump administration combating epidemic of youth e-cigarette use with plan to clear market of Unauthorized, Non-Tobacco-Flavored e-cigarette products; 2019.

25. Giovenco DP, Hammond D, Corey CG, et al. E-Cigarette market trends in traditional U.S. retail channels, 2012-2013. Nicotine Tob Res 2015;17:1279-83.

26. O'Connor RJ, Fix BV, McNeill A, et al. Characteristics of nicotine vaping products used by participants in the 2016 ITC four country smoking and Vaping survey. Addiction 2019;16.

27. Berg CJ. Preferred flavors and reasons for e-cigarette use and discontinued use among never, current, and former smokers. Int J Public Health 2016;61:225-36.

28. Russell C, McKeganey N, Dickson T, et al. Changing patterns of first e-cigarette flavor used and current flavors used by 20,836 adult frequent e-cigarette users in the USA. Harm Reduct J 2018;15:33.

29. European Commission. EU common entry gate (EU-CEG), 2016. Available: https://ec. europa.eu/health/euceg/introduction_en

30. Krüsemann EJZ, Boesveldt S, de Graaf K, et al. An E-Liquid flavor wheel: a shared vocabulary based on systematically reviewing E-Liquid flavor classifications in literature. Nicotine Tob Res 2019;21:1310-9.

31. McHugh ML. Interrater reliability: the kappa statistic. Biochem Med 2012;22:276-82.

32. Farsalinos KE, Romagna G, Tsiapras D, et al. Impact of flavour variability on electronic cigarette use experience: an Internet survey. Int J Environ Res Public Health 2013;10:7272-82.

33. Hoffman AC, Salgado RV, Dresler C, et al. Flavour preferences in youth versus adults: a review. Tob Control 2016;25:ii32-9.

34. Dutch Government. Regeling van de Staatssecretaris van Volksgezondheid, Welzijn en sport van 23 April 2018, kenmerk 1220157-166930-WJZ, houdende wijziging van de Tabaks- en rookwarenregeling TER regeling van de elektronische sigaret zonder nicotine en nadere regeling van voor roken bestemde kruidenproducten en nadere verpakkingseisen voor roken bestemde tabaksproducten, 2018. Available: https:// zoek.officielebekendmakingen.nl/stcrt-2018-23779.html 